\title{
Implementasi Algoritma Goverment Standard (GOST) dalam Pengamanan File Dokumen
}

\author{
Sugiarti $^{\mathrm{a}, 1}$, Mirnawati $^{\mathrm{a}, 2}$ \\ ${ }^{a}$ Universitas Muslim Indonesia, Jl. Urip Sumoharjo KM.5, Makassar 90231, Indonesia \\ ${ }^{1}$ sugiarti.sugiarti@umi.ac.id; ${ }^{2} 13020110134 @ u m i . a c . i d$
}

\begin{tabular}{|c|c|}
\hline INFORMASI ARTIKEL & ABSTRAK \\
\hline $\begin{array}{ll}\text { Diterima } & : 10-04-2020 \\
\text { Direvisi } & : 24-05-2020 \\
\text { Diterbitkan } & : 31-07-2020\end{array}$ & $\begin{array}{l}\text { Dokumentasi dalam teknologi saat ini adalah hal yang tak dapat } \\
\text { terlepas dari kebutuhan suatu lembaga atau instansi dimana dokumen } \\
\text { adalah hal yang paling sering digunakan baik dalam bentuk dokumen } \\
\text { manual maupun dalam bentuk file teks dalam komputer. Oleh karena } \\
\text { itu,.keamanan data atau dokumen rahasia sangat dibutuhkan dalam bisnis } \\
\text { maupun pribadi. Tetapi dalam pengiriman atau pengamanan file data yang } \\
\text { bersifat rahasia masih kurang dalam sistem keamanan data. Maka dari itu } \\
\text { perlu keamanan tambahan untuk proses penyimpanan file baik itu file yang } \\
\text { di rasa pribadi maupun data dalam keorganisasian dengan menggunakan } \\
\text { proses enkripsi dan deskripsi menggunakan metode Government Standard } \\
\text { (GOST). Maka data penting dapat lebih terjaga dan dengan adanya aplikasi } \\
\text { ini kita dapat mengenkripsi data untuk menjaga kerahasiaan file yang kita } \\
\text { simpan. Aplikasi ini dibangun dengan menggunakan Visual Studio } 2010 \text {. }\end{array}$ \\
\hline & $(\mathrm{cc})) \mathrm{BY}-\mathrm{NC}$ \\
\hline
\end{tabular}

\section{Pendahuluan}

Informasi secara umum dapat disampaikan dalam bentuk suara, simbol-simbol teks, tetapi dalam dunia teknologi sekarang ini kita tidak dapat lepas dari sistem komputerisasi yang digunakan sehari-hari untuk menunjang kegiatan manusia baik itu dalam bentuk dokumen maupun secara umum dalam bidang kegiatan komputerisasi sehari-hari di setiap perusahaan maupun organisasi-organisasi yang secara umum sifatnya adalah privasi. Informasi yang ingin disampaikan dapat menjadi suatu hal yang sangat berharga bagi seseorang maupun badan organisasi maka dari itu dibutuhkan adanya keamanan informasi.

Keamanan informasi yang sering digunakan adalah informasi dalam bentuk dokumen dimana doukumen itu sifatnya sangat penting sekarang ini karena banyak orang maupun badan organisasi yang ingin mendapatkan informasi dari orang lain atau badan organisasi lain. Persaingan memaksa orang untuk dapat melakukan sesuatu hal yang dengan cara kejahatan yaitu mengambil dokumen tanpa sepengetahuan pihak organisasi maupun perorangan untuk mendapatkan informasi yang mereka inginkan. Perkembangan teknologi sekarang ini tidak lepas dari internet atau jaringan lokal dimana keamanan data dokumen tidak dapat dijamin keamanannya. Teknologi internet telah menjadi sarana komunikasi dan bertukar informasi bagi masyarakat. Internet merupakan fasilitas umum dimana keamanan informasinya dapat dikatakan tidak aman bagi dokumen rahasia yang ingin di sampaikan ke pihak yang dituju.

Besar kemungkinan dokumen dapat diakses atau dicuri oleh orang yang tidak berkepentingan, maka diperlukan suatu pengamanan informasi dengan menyampaikan pesan dalam bentuk chiper text dimana chiper text ini adalah hasil dari enkripsi sehingga informasi tersebut hanya orang yang berhak saja yang dapat mengetahui plain text atau hasil dari dekripsi dari informasi tersebut. Banyak algoritma yang dapat digunakan untuk melakukan keamanan dokumen salah satunya dengan mengimplementasikan algoritma Goverment Standard (GOST).

Berdasarkan latar belakang tersebut, maka Penulis menggunakan metode Goverment Standard (GOST) dikarenakan algoritma tersebut masih kurang digunakan sehingga baik di implementasikan dalam keamanan file dokumen. 


\section{Metode}

\section{A. Kriptografi}

Menurut Rinaldi Munir (2006:2), kriptografi (Cryptography) berasal dari bahasa yunani: "cryptos" artinya "secret" (rahasia), sedangkan "graphein" artinya "writing" (tulisan). Jadi, kriptografi berarti "secret writing" atau tulisan rahasia. Beberapa buku telah mendefenisikan kriptografi seperti yang telah didefenisikan oleh buku-buku lama (sebelum tahun 1980-an) menyatakan bahwa kriptografi adalah ilmu dan seni untuk menjaga kerahasian pesan dengan cara menyandikan ke dalam bentuk yang tidak dapat lagi dimengerti maknanya. Pada masa lalu kriptografi digunakan untuk keamanan komunikasi penting seperti komunikasi di kalangan militer, diplomat dan mata-mata. Namum saat ini kriptografi digunakan tidak hanya untuk komunikasi penting tetapi digunakan untuk tujuan integrity, authentication dan nonrepudition.

Sejarah awal kriptografi, setiap orang mempunyai cara sendiri yang unik untuk merahasiakan pesan. Perbedaan cara yang unik dalam merahasiakan pesan sehingga pesan rahasia mempunyai nilai estetika tersendiri. Sejak dahulu hingga sekarang teknik kriptografi terus berkembang. Pada perkembangan kedepanya, kriptografi akan menjadi sebuah disiplin ilmu sendiri karena teknik-teknik kriptografi dapat diformulasikan secara matematik sehingga menjadi sebuah metode yang formal.

\section{B. Algoritma Goverment Standard (GOST)}

GOST merupakan singkatan dari "Gosundarstvennyi Standard" atau "Goverment Standard". Algoritma ini merupakan suatu algoritma block cipher yang dikembangkan oleh seorang berkembangasaan Uni Soviet, dan digunakan untuk meneyembunyikan data atau informasi yang bersifat rahasaia pada saat berkomunikasi. Algoritma inin merupakan suatu algoritma enkripsi sederhana yang memiliki jumlah proses sebanyak 32 round ( putaran) dan menggunakan 64 bit blok chiper dengan 256 bit key. Algoritma GOST juga menggunakan tabel S-box yang berbeda-beda dan operasi XOR serta Left Circular Shift (Muh Manahan PS, Andri H, Jurnal Ilmiah Universitas Kristen Indonesia Teknik Informatika, VoI, 1, Nomor 2, Juli 2004).

Kelemahan GOST yang diketahuai sampai saat ini adalah karena key sechudele - nya yang sederhana sehingga pada keadaan tertentu menjadi titik lemahnya terhadap metode kriptanalisis seperti Related-key Cyptanalysis. Tetapi hal ini dapat diatasi dengan melewatkan kunci kepada fungsi hash yang kuat secara kriptografi seperti SHA -I, kemudian menggunakan hasil hash untuk input inisialisasi kunci. Kelebihan dari GOST ini adalah kecepatannya yang cukup baik, walaupun tidak secepat Blowfish tetapi lebih cepat dari IDEA. Komponen dari algoritma GOST antara lain :

1. Key Share Unit (KSU) menyimpan 256 bit string dengan menggunakan 32 bit register (K0, K1, ...,K7).

2. Dua Buah 32 bit register $(\mathrm{R} 1, \mathrm{R} 2)$

3. 32 bit adder modulo 232 (CMI)

4. Bitwise adder XOR (CM2)

5. Subtitusion block (S) yaitu berupa 8 buah 64 bit S- Box.

6. Rotasi Left Shift register (R) sebanyak 11 bit.

\section{Proses Pembentukan Kunci}

Proses pembentukan kunci dapat di lihat dalam penjabaran berikut ini :

1. Input key berupa 256 bit key dengan perincian k1, k2, k3, ..., k256.

2. Input key tersebut dikelompokan dan dimasukkan ke dalam 8 buah KSU dengan aturan seperti berikut,

$$
\mathrm{K} 1=(\mathrm{k} 32, \ldots, \mathrm{k} 1)
$$

$\mathrm{K} 2=(\mathrm{k} 64, \ldots, \mathrm{k} 33)$

$\mathrm{K} 3=(\mathrm{k} 96, \ldots, \mathrm{k} 65)$

$\mathrm{K} 4=(\mathrm{k} 128, \ldots, \mathrm{k} 97)$

$\mathrm{K} 5=(\mathrm{k} 160, \ldots, \mathrm{k} 129)$

$\mathrm{K} 6=(\mathrm{k} 192, \ldots, \mathrm{k} 161)$

$\mathrm{K} 7=(\mathrm{k} 224, \ldots, \mathrm{k} 193)$

$\mathrm{K} 1=(\mathrm{k} 256, \ldots, \mathrm{k} 225)$

\section{Proses Enkripsi}

Proses enkripsi dengan metode GOST untuk satu putaran (iterasi), dapat dilihat pada penjabaran berikut ini,

1. 64 bit plaintext dibagi menjadi 2 buah bagian 32 bit, yaitu Li dan Ri.

Caranya : Input a1 $(0), \ldots$, a32(0), ..., b1 $(0), \ldots(0)$

$\mathrm{R} 0=\mathrm{a} 32(0), \mathrm{a} 31(0), \ldots, \mathrm{a} 1(0)$

$\mathrm{L} 0=\mathrm{b} 32(0), \mathrm{b} 31(0), \ldots, \mathrm{b} 1(0)$

2. $(\mathrm{Ri}+\mathrm{Ki})$ mod 232. Hasil dari penjumlahan modulo 232 berupa 32 bit

3. Hasil dari penjumlahan modulo 232 dibagi menjadi 8 bagian, dimana masing-masing bagian terdiri dari 4 bit. Setiap bagian dimasukkan ke dalam tabel S-Box yang berbeda, 4 bit pertama menjadi input dari SBox kedua dan seterusnya. 
4. Hasil yang didapat dari subtitusi ke S-Box dan digabungkan kembali menjadi 32 bit dan kemudian dilakukan rotasi left shift sebanyak 11 bit.

5. $\mathrm{Ri}+\mathrm{I}=\mathrm{Ri}$ (hasil dari rotate left shift) XOR Li.

6. $\mathrm{Li}+\mathrm{I}=\mathrm{Ri}$ sebelum dilakukan proses Proses pembentukan kunci modulo, S-BOX, Rotate left Shift dilakukan sebanyak 32 kali (putaran) dengan penggunaan kunci pada masing-masing (putaran) dengan penggunaan kunci pada masing-masing putaran berbeda-beda sesuai dengan putaran berbeda-beda sesuai dengan aturan berikut ini.

Putaran $0-7 \quad:$ K0,KI,K2,..., K7

Putaran $8-15 \quad:$ K0,KI,K2,..., K7

Putaran $16-23 \quad:$ K0,KI,K2,..., K7

Putaran $24-31 \quad: \mathrm{K} 7, \mathrm{~K} 6, \mathrm{k} 5, \ldots, \mathrm{K} 7$

Untuk putaran ke-31, langkah 5 dan 6 agak sedikit berbeda langkah 5 dan 6 untuk putaran 31 adalah sebagai berikut,

$\mathrm{R} 32=\mathrm{R} 31$ sebelum dilakukan proses

L32=L31 XOR R31 Sehingga chipertext yang dihasilkan adalah

$\mathrm{L} 32: \mathrm{b}(32), \mathrm{b}(31), \ldots ., \mathrm{b}(1)$

$\mathrm{R} 32: \mathrm{a}(32), \mathrm{a}(31), \ldots . ., \mathrm{a}(1)$

$\mathrm{T}=\mathrm{a}(1), \ldots . ., \mathrm{a}(32), \mathrm{b}(1), \ldots . \mathrm{b}(32)$

\section{Proses Dekripsi}

Proses dekripsi merupakan proses kebalikan dari proses enkripsi, penggunaan kunci pada masingmasing putaran pada proses dekripsi adalah sebagai berikut,

$\begin{array}{lr}\text { Putaran } 0-7 & : \mathrm{K} 0, \mathrm{KI}, \mathrm{K} 2, \ldots, \mathrm{K} 7 \\ \text { Putaran } 8-15 & : \mathrm{K} 7, \mathrm{~K} 6, \mathrm{~K} 5, \ldots, \mathrm{K} 0 \\ \text { Putaran 16-23 } & : \mathrm{K} 7, \mathrm{~K} 6, \mathrm{~K} 5, \ldots, \mathrm{K} 0 \\ \text { Putaran 24-31 } & : \mathrm{K} 7, \mathrm{~K} 6, \mathrm{k} 5, \ldots, \mathrm{K} 0\end{array}$

Algoritma yang digunakan untuk proses dekripsi sama dengan proses enkripsi dengan aturan untuk langkah 5 dan 6 pada putaran ke-31 adalah sebagai berikut,

R32 - R31 sebelum dilakukan proses, L32 = R31 XOR L31.

Plaintext yang dihasilkan pada proses dekripsi adalah,

$\mathrm{L} 32$ - b(32), b(31),....., b(1)

$\mathrm{R} 32-\mathrm{a}(32), \mathrm{a}(31), \ldots \ldots . ., \mathrm{a}(1)$

$\mathrm{P}-\mathrm{a}(1), \ldots \ldots ., \mathrm{a}(32), \mathrm{b}(1), \ldots ., \mathrm{b}(32)$,

Implementasi Hardware dan Software GOST

1. GOST sudah diimplementasikan dalam bentuk perangkat keras.

2. Dalam bentuk perangkat keras, GOST diimplementasikan di dalam chip. Setiap detik chip ini dapat mengenkripsikan 16,8 juta blok (atau 1 gigabit per detik).

3. Implementasi GOST ke dalam perangkat lunak dapat melakukan enkripsi 32.000 blok per-detik (pada komputer mainframe IBM 3090).

\section{Hasil dan Pembahasan}

Analisis algoritma dibutuhkan untuk mengetahui perhitungan secara umum bagaimana perhitungan tersebut menjadi file dokumen seperti contoh berikut:

Diberikan contoh:

- Plaintext $(\mathrm{x})=$ COMPUTER

- $\operatorname{Key}(\mathrm{k})=13345779$ 9B BC DF F1

Langkah Pertama :

Ubahlah plaintext kedalam bentuk biner

C : 01000011

$\mathrm{O}: 01001111$

$\mathrm{M}: 01001101$

$\mathrm{P}: 01010000$

$\mathrm{U}: 01010101$

$\mathrm{T}: 01010100$

E : 01000101

$\mathrm{R}: 01010010$ 
Ubahlah key kedalam bentuk biner

$13: 00010011$

$34: 00110100$

$57: 01010111$

$79: 01111001$

9B : 10011011

$\mathrm{BC}: 10111100$

DF : 11011111

F1 : 11110001

Langkah Kedua :

Lakukan Initial Permutation (IP) pada bit plaintext menggunakan tabel IP berikut:

Tabel 1. Initial Permutation (IP)

\begin{tabular}{|l|l|l|l|l|l|l|l|}
\hline 58 & 50 & 42 & 34 & 26 & 18 & 10 & 2 \\
\hline 60 & 52 & 44 & 36 & 28 & 20 & 12 & 4 \\
\hline 62 & 54 & 46 & 38 & 30 & 22 & 14 & 6 \\
\hline 64 & 56 & 48 & 40 & 32 & 24 & 16 & 8 \\
\hline 57 & 49 & 41 & 33 & 25 & 17 & 9 & 1 \\
\hline 59 & 51 & 43 & 35 & 27 & 19 & 11 & 3 \\
\hline 61 & 53 & 45 & 37 & 29 & 21 & 13 & 5 \\
\hline 63 & 55 & 47 & 39 & 31 & 23 & 15 & 7 \\
\hline
\end{tabular}

Urutan bit pada plaintext urutan ke 58 ditaruh diposisi 1 ,

Urutan bit pada plaintext urutan ke 50 ditaruh di posisi 2,

Urutan bit pada plaintext urutan ke 42 ditaruh di posisi 3, dst

Sehingga hasil outputnya adalah

IP(x) : 1111111110111000011101100101011100000000000000000000011010000011

Pecah bit pada IP(x) menjadi 2 bagian yaitu:

$\mathrm{L}_{0}: 11111111101110000111011001010111$ (tabel IP dengan warna Putih) $\mathrm{R}_{0}: 0000000000000000$

0000011010000011 (tabel IP dengan warna Merah)

\section{Langkah Ketiga :}

proses key yang di gunaka nuntuk mengenkripsi plaintext dengan menggunakan tabel permutasi kompresi 1, pada langkah ini terjadi kompresi dengan membuang 1 bit masing-masing blok kunci dari 64 bit menjadi 56 bit.

Tabel 2. PC-1

\begin{tabular}{|c|c|c|c|c|c|c|c|}
\hline 57 & 49 & 41 & 33 & 25 & 17 & 9 \\
\hline 1 & 58 & 50 & 42 & 34 & 26 & 18 \\
\hline 10 & 2 & 59 & 51 & 43 & 35 & 27 \\
\hline 19 & 11 & 3 & 60 & 52 & 44 & 36 \\
\hline 63 & 55 & 47 & 39 & 31 & 23 & 15 \\
\hline 7 & 62 & 54 & 45 & 38 & 30 & 22 \\
\hline 14 & 6 & 61 & 53 & 45 & 37 & 29 \\
\hline 21 & 13 & 5 & 28 & 20 & 12 & 4 \\
\hline
\end{tabular}

Dapat kita lihat pada tabel diatas, tidak terdapat urutan bit 8,16,24,32,40,48,56,64 karena telah dikompress. Berikut hasil outpunya :

$\mathrm{CD}(\mathrm{k})$ : 11110000110011001010101011110101010101100110011110001111

Pecah $\mathrm{CD}(\mathrm{k})$ menjadi dua bagian kiri dan kanan, sehingga menjadi 
$\mathrm{C}_{0}: 1111000011001100101010101111$ (tabel PC-1 warna Putih)

$\mathrm{D}_{0}$ : 0101010101100110011110001111 (tabel PC-1 warna Merah)

Sehingga Input:

$\mathrm{R}_{16} \mathrm{~L}_{16}=\quad \begin{array}{llllllll}00011111 & 10010111 & 10100101 & 11100110 & 01101110 & 10100010 & 10101000 & 10110001\end{array}$

Menghasilkan Output:

Cipher(dalam biner) = 0101011011110001110101011100100001010010101011111000000100111111 Setelah didapatkan nilai biner maka bit yang telah dipecah tadi diubah mejadi file dokumen sesuai format file yang diambil.

\section{Kesimpulan}

Berdasarkan hasil penelitian dan pembahasan, serta pengujian perangkat lunak yang telah diuraikan pada bab-bab sebelumnya, maka dapat ditarik kesimpulan sebagai berikut:

1. Berdasarkan hasil pengujian perangkat lunak Aplikasi keamanan file menggunakan metode government Standard Berbasis Visual Studio.Net, telah bebas dari kesalahan program dan logika sehingga dapat mengatasi permasalahan yang ada pada sistem yang berjalan.

2. Dengan adanya aplikasi keamanan file menggunakan metode government Standard ini maka diharapkan file dokumen yang telah dienkripsi dapat terjaga keamanannya.

\section{Daftar Pustaka}

[1] H. Azis, "Network steganography system using covert channel for LSBS stego data on VOIP communication," Int. J. Eng. Adv. Technol., vol. 8, no. 5, pp. 1448-1449, 2019.

[2] H. Azis and F. Fattah, "Analisis Layanan Keamanan Sistem Kartu Transaksi Elektronik Menggunakan Metode Penetration Testing," Ilk. J. Ilm., vol. 11, no. 2, p. 167, 2019.

[3] A. Djamalilleil, M. Muslim, Y. Salim, E. I. Alwi, H. Azis, and Herman, "Modified Transposition Cipher Algorithm for Images Encryption," Proc. - 2nd East Indones. Conf. Comput. Inf. Technol. Internet Things Ind. EIConCIT 2018, pp. 1-4, 2018.

[4] M. Nazeri, A. Rezai, and H. Azis, “An Efficient Architecture for Golay Code Encoder,” Proc. - 2nd East Indones. Conf. Comput. Inf. Technol. Internet Things Ind. EIConCIT 2018, pp. 114-117, 2018.

[5] F. Muharram, H. Azis, and A. R. Manga, "Analisis Algoritma pada Proses Enkripsi dan Dekripsi File Menggunakan Advanced Encryption Standard (AES)," Pros. Semin. Nas. Ilmu Komput. dan Teknol. Inf., vol. 3, no. 2, pp. 112-115, 2018.

[6] Y. Salim and H. Azis, "Metode Digital Watermark Pada File Penelitian Dosen," Ilk. J. Ilm., vol. 9, no. 2, pp. 161-166, 2017.

[7] H. Azis and R. Wardoyo, "Penerapan Network Steganography Menggunakan Metode Modifikasi LACK Dan Layanan Message Authentication Code Pada Voip Network Steganography System with modification of LACK and Message Authentication Code on VoIP," Semin. Nas. Komun. dan Inform., pp. 13-19, 2015. 